\title{
Rutting Causes Analysis on Yi-Huai-Jiang Expressway
}

\author{
Jian $\mathrm{LI}^{1}$, Fujian $\mathrm{NI}^{2}$, Xiang $\mathrm{MA}^{3}$, Cheng $\mathrm{LING}^{4}$ \\ 1 College of Transportation Engineering, Southeast University, 2\# Sipailou, \\ Nanjing, ST 210096, P.R.China; PH (086) 25-8379-4931; FAX (086) \\ 25-8379-4931; email: heroring@163.com. \\ ${ }^{2}$ College of Transportation Engineering, Southeast University, 2\# Sipailou, \\ Nanjing, ST 210096, P.R.China; PH (086) 25-8379-4931; FAX (086) \\ 25-8379-4931; email: nifujian@gmail.com. \\ 3 College of Transportation Engineering, Southeast University, 2\# Sipailou, \\ Nanjing, ST 210096, P.R.China; PH (086) 25-8379-4931; FAX (086) \\ 25-8379-4931; email: mxfst@sina.com. \\ 4 College of Transportation Engineering, Southeast University, 2\# Sipailou, \\ Nanjing, ST 210096, P.R.China; PH (086) 25-8379-4931; FAX (086) \\ 25-8379-4931; email: mylean@126.com.
}

\begin{abstract}
The Yi-Huai-Jiang Expressway is part of the main passage from Beijing to Shanghai. Serious rutting distresses have developed since it was opened. The causes of the rutting should be the key factor considered for treatment of the ruts. The causes of rutting on the Yi-Huai-Jiang Expressway are studied in this paper. First, typical sections with rutting distresses were selected. By comparing the thicknesses of core samples from each layer, the types of ruts and their occurring layers were determined. Secondly, the rutting-resistant properties of the core samples were evaluated by the Flow Number Test and compared between different sections. Third, traffic loads of each section were analyzed and compared. Finally, it was concluded that the poor rutting-resistant property of the middle layer, which is significantly affected by voids and the passing rate of $4.75 \mathrm{~mm}$ sieve, results in flowing ruts in this layer in the Shanghai-Beijing direction. It was determined that overloading of the road was causing compacting ruts in the bottom layer in the Beijing-Shanghai direction.
\end{abstract}

\section{INTRODUTION}

The Yi-Huai-Jiang Expressway is part of the main passage from Beijing to Shanghai, and also the axle wire of the highway network in the Jiangsu Province. It was opened to traffic in December 2000, and has been in operation for over ten years. As a primary expressway which connects the South and the North of China, it is filled with heavy traffic and many trucks. Serious rutting distresses have developed on this expressway since it was opened. There are two lanes in each direction of the expressway. The carriageway suffers severe ruts because a majority of the traffic volume consists of truck traffic. The length of the section of 
carriageway with an average rutting depth over $15 \mathrm{~mm}$ accounts for nearly $20 \%$ of the total length according to a survey conducted in 2008, and this proportion is increasing year by year. Obviously, the rutting distress seriously affects the service quality and life of the expressway, and effective measures should be taken.

Semi-rigid bases and asphalt pavement were adopted in this expressway. The surface course contains three layers: upper layer, middle layer and bottom layer. The upper layer uses an AK-16 modified asphalt mixture, and the other layers select an AC-25 normal asphalt mixture. Generally, the semi-rigid base and the courses below have little deformation because of high strength and stiffness, and ruts caused by traffic loads and high temperature mainly occur in the asphalt pavement surface course (Sha 2001). Usually the upper layers and middle layers have a greater possibility to succumb to rutting distresses due to the higher shearing stresses that they bear. Based on the views above, two treatment measures for rutting distresses are adopted on this expressway. One is thin overlay, and the other is milling and repaving the top two layers to deal with heavy ruts. However, the actual rutting situation after being treated indicates that the two measures are ineffective in some rutting sections. Considering the specificity of each rutting section, it is unreasonable to handle each rutting distress with the same measure. The characteristics and causes of the rutting distress should be studied first, and then the relevant treatment measures could be proposed.

This paper demonstrates the causes of rutting distress on the Yi-Huai-Jiang Expressway. There are many rutting sections so it is difficult to analyze all of them. Therefore, typical sections with heavy ruts are selected based on average rutting depth, traffic volume, treatment history, etc. The influence of traffic volume and rutting-resistant properties of the surface course on rutting formation are focused on in this paper. The analysis of the rutting-resistant property of the surface course is based on core samples from the sites.

\section{CHARACTERISTICS OF RUTTING DISTRESS}

Four sections with heavy rutting distresses were selected with two in each direction, and another four sections with light rutting distress were also chosen for comparison. The information of these sections is summarized in Table 1, including range of stake number, rutting depth, ESALs, and maintenance history. The average rutting depth was gained by the road rutting survey in 2009. According to the Highway Performance Assessment Standards of China, when the rutting depth is more than $15 \mathrm{~mm}$, the rutting grade is defined as "Heavy". Otherwise, the grade is defined as "Light". Sections 1-4 are in the Shanghai-Beijing direction, and sections 5-8 are in the Beijing-Shanghai direction.

\section{Rutting Type and Position}

Surface layer core samples were taken from the wheel path and non-wheel path of the carriageway and shoulder in each section. The thicknesses of the core samples were measured. The layer where the rutting occurred and the type of rutting could be determined by comparing the thickness of each layer of the cores 
from different sites. The deformation of each layer can be expressed by deformation quantity and ratio. The thickness of each layer of the cores from the shoulder could be seen as the initial thickness of each layer of the carriageway, because the deformation of the shoulder could be ignored due to the light traffic it received. Deformation quantity is the difference between the thickness of the shoulder core and the thickness of the wheel path core. Deformation ratio means the ratio of deformation quantity to the thickness of shoulder core. Table 2 summarizes the deformation quantities and ratios of each layer in the wheel path of the carriageway.

Table 1. Information of Selected Sections

\begin{tabular}{|c|c|c|c|c|}
\hline No. & $\begin{array}{l}\text { Stake Number } \\
\text { Range }\end{array}$ & $\begin{array}{c}\text { Average } \\
\text { Rutting } \\
\text { Depth } \\
(\mathrm{mm}) \\
\end{array}$ & $\begin{array}{c}\text { Rutting } \\
\text { Level }\end{array}$ & Maintenance History \\
\hline 1 & $\begin{array}{l}\mathrm{K} 33+730 \\
-\mathrm{K} 34+110\end{array}$ & 24.0 & heavy & $\begin{array}{l}\text { Overlaid modified asphalt } \\
\text { mixture with } 1 \mathrm{~cm} \text { depth in } \\
2005\end{array}$ \\
\hline 2 & $\begin{array}{l}K 80+400 \\
-K 80+700\end{array}$ & 5.3 & light & $\begin{array}{l}\text { Overlaid modified asphalt } \\
\text { mixture with } 1 \mathrm{~cm} \text { depth in } \\
2005\end{array}$ \\
\hline 3 & $\begin{array}{l}\mathrm{K} 221+670 \\
-\mathrm{K} 221+830\end{array}$ & 18.0 & heavy & None \\
\hline 4 & $\begin{array}{l}\mathrm{K} 222+570 \\
-\mathrm{K} 222+770\end{array}$ & 4.1 & light & None \\
\hline 5 & $\begin{array}{l}\mathrm{K} 6+840 \\
-\mathrm{K} 6+960\end{array}$ & 21.5 & heavy & $\begin{array}{c}\text { Overlaid modified asphalt } \\
\text { mixture with } 1 \mathrm{~cm} \text { depth in } 005\end{array}$ \\
\hline 6 & $\begin{array}{l}\mathrm{K} 107+200 \\
-\mathrm{K} 107+490\end{array}$ & 4.9 & light & None \\
\hline 7 & $\begin{array}{l}\mathrm{K} 259+860 \\
-\mathrm{K} 259+980\end{array}$ & 17.8 & heavy & None \\
\hline 8 & $\begin{array}{l}\mathrm{K} 86+870 \\
-\mathrm{K} 87+000\end{array}$ & 4.9 & light & $\begin{array}{l}\text { Milled and repaved the whole } \\
\text { surface layer in } 2005\end{array}$ \\
\hline
\end{tabular}

Table 2. Deformation Quantity and Ratio of Each Layer

\begin{tabular}{c|c|c|c|c|c|c}
\hline \multirow{2}{*}{ Site } & \multicolumn{2}{|c|}{ Upper Layer } & \multicolumn{2}{c|}{ Middle Layer } & \multicolumn{2}{c}{ Bottom Layer } \\
Quantity & $\begin{array}{c}\text { Ratio } \\
(\mathbf{m m})\end{array}$ & $\begin{array}{c}\text { Quantity } \\
(\mathbf{\%})\end{array}$ & $\begin{array}{c}\text { Ratio } \\
(\mathbf{m m})\end{array}$ & $\begin{array}{c}\text { Quantity } \\
(\mathbf{m m})\end{array}$ & $\begin{array}{c}\text { Ratio } \\
(\mathbf{\%})\end{array}$ \\
\hline $\mathrm{K} 33+960$ & 2.0 & 3.9 & 9.6 & 19.1 & 4.6 & 5.8 \\
$\mathrm{~K} 221+780$ & 3.3 & 7.3 & 8.0 & 15.5 & 0 & 0 \\
K6+960 & 0 & 0 & 3.0 & 6.0 & 13.4 & 18.7 \\
K259+960 & 0 & 0 & 2.3 & 4.5 & 13.0 & 16.6 \\
\hline
\end{tabular}

As is seen in Table 2, the middle layer has the largest deformation quantity 
and ratio in $\mathrm{K} 33+960$ (section 1) and $\mathrm{K} 221+780$ (section 3), while the bottom layer does in $\mathrm{K} 6+960$ (section 5) and $\mathrm{K} 259+960$ (section 7). The ruts occur mainly in the middle layer in the first two sections which are both in the Shanghai-Beijing direction, and in the bottom layer in the other two sections which are both in the Beijing-Shanghai direction. In order to analyze rutting types, the thickness of middle layer cores in section 1 and 3 and the thickness of bottom layer cores in section 5 and 7 are compared in Figure 1.

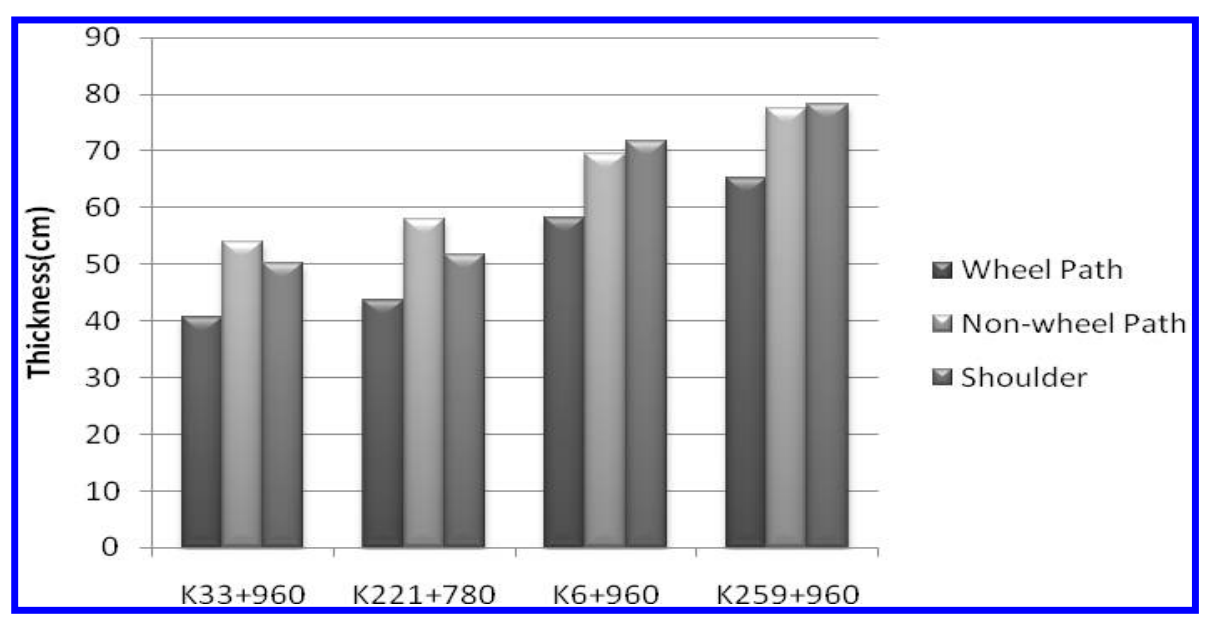

Figure 1. Thickness of Rutting Layer Cores

The descending order of thickness of middle layer cores in K33+960 and K221+780 is non-wheel path, shoulder and wheel path. There was obvious intumesce on the non-wheel path of carriageway. This conclusion indicates that flowing deformation occurs in the middle layer of the wheel path, which leads to the increase of the thickness of middle layer in the non-wheel path. So the main rutting type of section 1 and 3 is determined to be flowing ruts.

The thickness of bottom layer cores of the shoulder and non-wheel path in K6+960 and K259+960 are almost the same, both thicker than that of the wheel path. Compared to sections 1 and 3, there was no intumesce on the non-wheel path in section 5 and 7. So it can be concluded that the bottom layer in the wheel path of the two sections in the Beijing-Shanghai direction has serious compacting ruts.

\section{COMPARISON OF RUTTING-RESISTANT PROPERTY OF EACH SECTION}

The rutting-resistant property of asphalt pavement exerts an important influence on rutting development. Middle layer cores and bottom layer cores from each section were tested to evaluate their properties.

Traffic situations of sections in the same direction are similar. Also, the climate along the whole expressway is comparable. So the rutting-resistant property of carriageway cores from light-rutting sections and heavy-rutting sections in the same direction can be compared to analyze whether it is what mainly accounts for the heavy ruts. 
The rutting-resistant property of cores is evaluated by the Flow Number test (Kaloush 2003) in this paper. Based on the original height, cores from the middle layer and bottom layer were cut to $5 \mathrm{~cm}$ and $6 \mathrm{~cm}$ in height, respectively. Testing temperature was $50^{\circ} \mathrm{C}$ for middle layer cores and $40^{\circ} \mathrm{C}$ for bottom layer cores. Axle stress was $700 \mathrm{KPa}$, and confining stress was $0 \mathrm{KPa}$. The loading cycle was $1 \mathrm{~s}$, including $0.1 \mathrm{~s}$ half-sine pressure and $0.9 \mathrm{~s}$ interval. The testing termination was after 10000 loading cycles, 5\% axle strains, or the creep curve arriving at the third stage (NCHRP 2003).

The test data are presented in Table 3 and Table 4. It is difficult to evaluate all the cores by Fn value because it isn't available in some tests. Studies showed that accumulative rate of the creep curve in the second stage was stable so it could be used to replace Fn as the evaluation index. Here we use k value to express the rate. A larger $\mathrm{k}$ means a higher deforming speed of asphalt mixture under loading, and also means a weaker rutting-resistant property of the cores. The Fn and k values are both used in this paper to estimate the testing results.

Table 3 Flow Number Test Results of Cores

\begin{tabular}{c|c|c|c|c|c}
\hline \multirow{2}{*}{$\begin{array}{c}\text { Stake } \\
\text { Number }\end{array}$} & Site & \multicolumn{2}{|c|}{ Middle Layer } & \multicolumn{2}{c}{ Bottom Layer } \\
& & Fn & $\mathbf{k}$ & Fn & kores \\
\hline K33+960 & Wheel Path & - & 37 & - & 24 \\
(Section 1) & Non-Wheel Path & 430 & 66 & 1500 & 22 \\
K80+440 & Wheel Path & - & 34 & 900 & 18 \\
(Section 2) & Non-Wheel Path & 700 & 45 & 710 & 27 \\
K221+780 & Wheel Path & & 29 & 5200 & 8 \\
(Section 3) & Non-Wheel Path & 600 & 18 & - & 9 \\
K222+630 & Wheel Path & 2200 & 5 & 2000 & 10 \\
(Section 4) & Non-Wheel Path & 4000 & 4 & 3600 & 5 \\
K6+960 & Wheel Path & - & 6 & 3000 & 5 \\
(Section 5) & Non-Wheel Path & - & 8 & - & 10 \\
K107+380 & Wheel Path & - & 0.7 & 3600 & 2 \\
(Section 6) & Non-Wheel Path & - & 0.6 & 3400 & 3 \\
K259+960 & Wheel Path & 4000 & 5 & - & 3 \\
(Section 7) & Non-Wheel Path & 4600 & 6 & - & 2 \\
K86+950 & Wheel Path & - & 0.5 & 3000 & 7 \\
(Section 8) & Non-Wheel Path & - & 0.9 & 4000 & 6 \\
\hline
\end{tabular}

1.Analysis on tests data of middle layer cores

(1) Shanghai-Beijing direction

Contrast the test results of the middle layer cores in the wheel path and non-wheel path respectively.

First, compare the core samples in wheel path. The average $\mathrm{k}$ values of cores in section $1 \sim 4$ are $51,34,25$ and 9, so the order of rutting-resistant property of the middle layer in the four sections is: section $4>3>2>1$. 
Then compare the core samples in the non-wheel path. The average Fn values of cores in section $1 \sim 4$ are 405, 700, 600 and 4000, so the order of rutting-resistant property of the middle layer in the four sections is: section $4>2>$ $3>1$.

Test results of cores in section 2 and 3 are similar, so the middle layers of the two sections have approximately the same rutting-resistant property. The order of rutting-resistant property of the middle layer in the four sections is available finally: section $4>2=3>1$.

(2) Beijing-Shanghai direction

Compare the core samples in wheel path. The average $\mathrm{k}$ values of cores in section $5 \sim 8$ are $6,0.7,2.6$ and 0.5 . So section 6 and 8 have the best rutting-resistant property in the bottom layer, being followed by section 7 , and then section 5 .

Then the core samples in non-wheel path are compared. The average $\mathrm{k}$ values of cores in section $5 \sim 8$ are $8,0.6,6$ and 0.9 . It can be seen that the results are close to those of the cores in the wheel path.

Compare the test results of all the core samples in the two directions. It is concluded that middle layers of section 1 and 3 which are impacted by heavy flowing ruts have the worst rutting-resistant property, while sections in Beijing-to-Shanghai direction have a much better status.

2. Analysis on test data of bottom layer cores

Test results of bottom layer cores are compared in same way as the middle layer cores. Test data is shown in the Table 5. The conclusions are:

In the Shanghai-Beijing direction, rutting-resistant property of the bottom layer of sections 3 and 4 is better than sections 1 and 2 .

In the Beijing-Shanghai direction, rutting-resistant properties of the bottom layer of the four sections are close to each other and better than sections in the other direction. Section 7 is the best, and section 5 is the worst. So it is concluded that the compacting ruts in the bottom layer in sections 5 and 7 are not obviously related with their rutting-resistant properties.

\section{TRAFFIC ANALYSIS}

The ESALs can not reflect general aspects of the traffic comprehensively. Therefore, the axle-load spectrum of the sections was analyzed in this paper.

\section{Axle-load spectrum}

It was investigated that there were nearly 50 axle combination types of trucks in this expressway, including the type of single axle and double wheels (type 1), the type of double axles and wheels (type 2), and the type of three axles and double wheels (type 3). These three types of trucks accounted for $75 \%$ of the total truck traffic (Liu 2008). Figures 2 4 summarize the axle-load spectrums of trucks of the three types. 


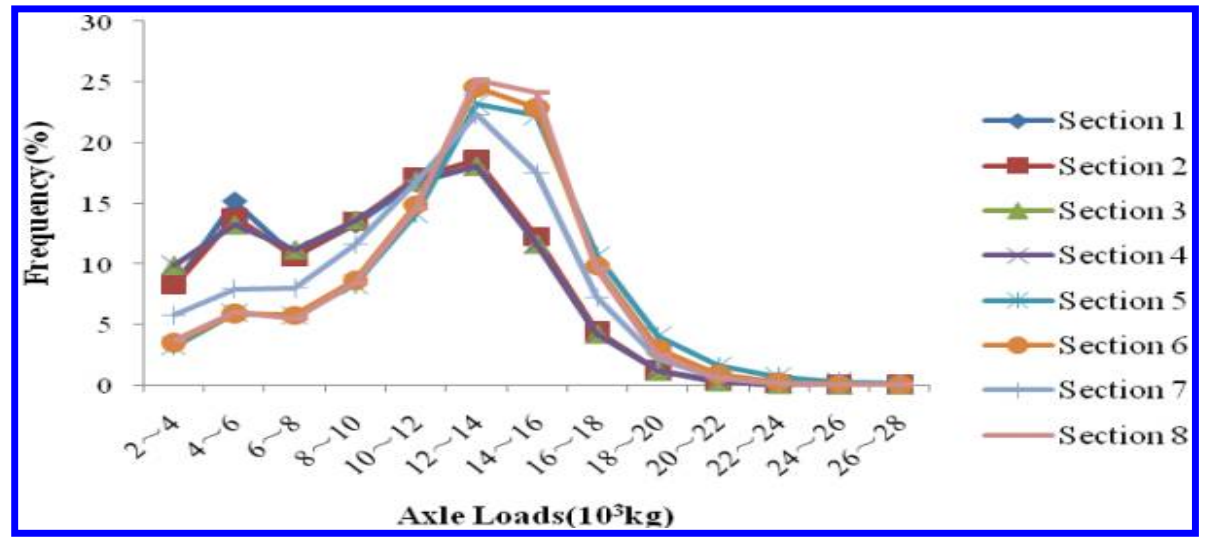

Figure 2. Axle-load Spectrum of Type 1

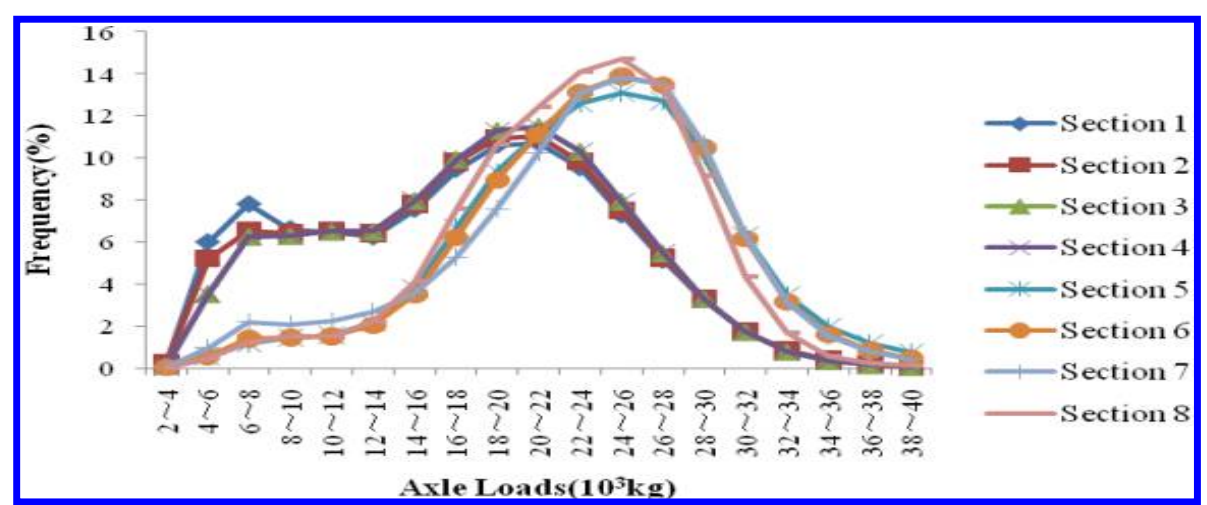

Figure 3. Axle-load Spectrum of Type 2

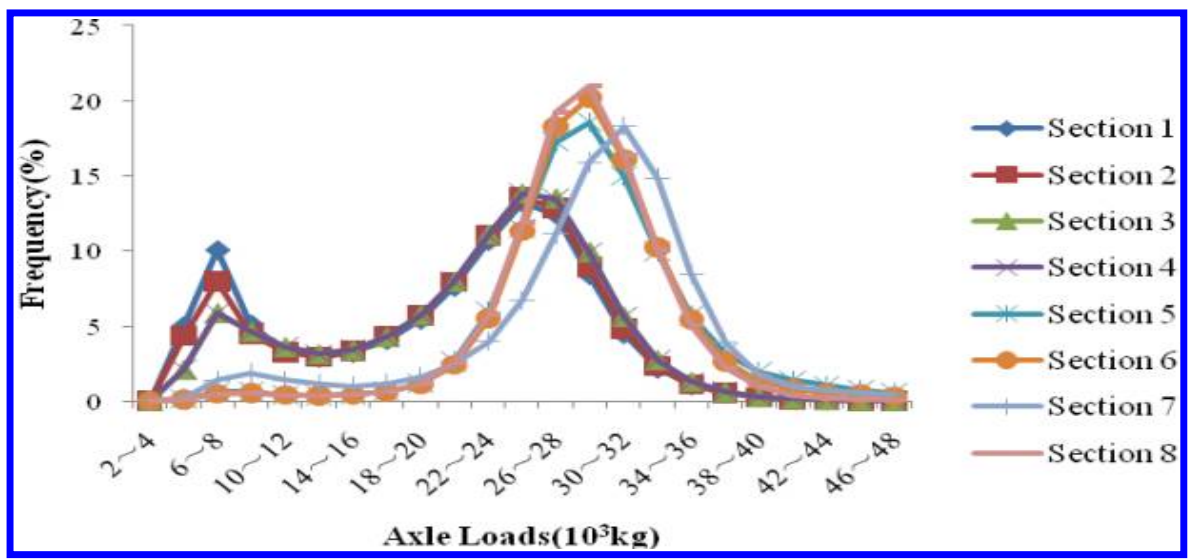

Figure 4. Axle-load Spectrum of Type 3

As is seen in the figures, the axle-load spectrums of sections in the same direction are almost the same. But there is a visible difference between the spectrums of the two different directions. The sections in the Beijing-to-Shanghai direction have endured much heavier traffic loads than sections in the Shanghai-to-Beijing direction. 


\section{Overloads Analysis}

The loads of trucks are limited in expressways in China. The maximum loads of the three types are: 6 tons for type 1, 10 tons for type 2, and 22 tons for type 3 . It could be seen in the axle-load spectrums that the trucks of three types have a serious overloading phenomenon. Table 4 shows the overloading ratio of the three types of trucks in each section during 2004 2008.

Table 4. Overloading Ratios of Trucks of Three Types (\%)

\begin{tabular}{c|c|c|c|c|c|c|c|c}
\hline \multirow{2}{*}{ Type } & \multicolumn{10}{c}{ Section No. } \\
& $\mathbf{1}$ & $\mathbf{2}$ & $\mathbf{3}$ & $\mathbf{4}$ & $\mathbf{5}$ & $\mathbf{6}$ & $\mathbf{7}$ & $\mathbf{8}$ \\
\hline 1 & 52.8 & 53.9 & 52.1 & 52.1 & 76.8 & 76.2 & 66.7 & 76.5 \\
2 & 49.7 & 51.1 & 52.1 & 52.1 & 82.6 & 83.3 & 81.0 & 81.3 \\
3 & 53.4 & 55.8 & 56.0 & 56.0 & 92.9 & 93.4 & 87.8 & 93.4 \\
\hline
\end{tabular}

The overloading ratios of the three types in sections of the Shanghai-Beijing direction are mostly in the range of $50 \%$ to $60 \%$, while the ratios in the Beijing-Shanghai direction reach over $90 \%$. Both directions have very high overloading ratios, resulting in the development of rutting distresses.

\section{ANALYSIS ON THE CAUSES OF RUTS}

Two factors were considered in analyzing the causes of rutting distress in sections 1, 3, 5, 7: traffic loads and rutting-resistant property of the surface course. The rutting causes of the two directions were analyzed respectively.

\section{Rutting Causes in Shanghai-Beijing Direction}

The traffic loads in the Shanghai-Beijing direction were much heavier than in the Beijing-Shanghai direction, so the possibility of heavy ruts developing in the Shanghai-Beijing direction was larger than in the other direction. But the fact was just the opposite. The results of Flow Number tests indicated that the rutting-resistant property of the middle layer in sections 1 and 3 was worse than in section 4 and all sections in the Beijing-Shanghai direction. Therefore, the only reason why the middle layers of sections 1 and 3 are filled with heavy flowing ruts is that the rutting-resistant property of their middle layer is insufficient.

\section{Rutting Causes in Beijing-Shanghai Direction}

The results of Flow Number tests indicated that the rutting-resistant property of the bottom layer in sections 5 and 7 didn't lead to heavy compacting rutting distress in this layer. It is known that ruts may develop quickly after the road is opened to traffic because the surface layer might be compacted under the traffic loads. The voids of cores in shoulder can show the initial state. The average voids of bottom layer cores in shoulder of sections 5 and 7 are $3.7 \%$ and $4.8 \%$, which indicates that the voids are not the reason for the rutting distress in the two sections.

The overloading ratio was very high in the Beijing-Shanghai direction. The 
traffic loads were so heavy in this direction that they would exert great pressure stress on the surface layer. It is supposed that a great compacting deformation takes place in the bottom layer under the pressure stress. This supposition is verified as follows.

Analyze the pressure in surface course under traffic loads. A finite element model was built by ABAQUS to calculate the pressure. Same material parameter values were adopted for each layer, including modulus of resilience as $1400 \mathrm{MPa}$ and Poisson's ratio as 0.35 . The thickness of the surface course was $18 \mathrm{~cm}$. Four different levels of axle load were chosen to analyze the effect of axle load on pressure. The tire pressure was $700 \mathrm{KPa}$. The maximum pressure curves are shown in Figure 5.

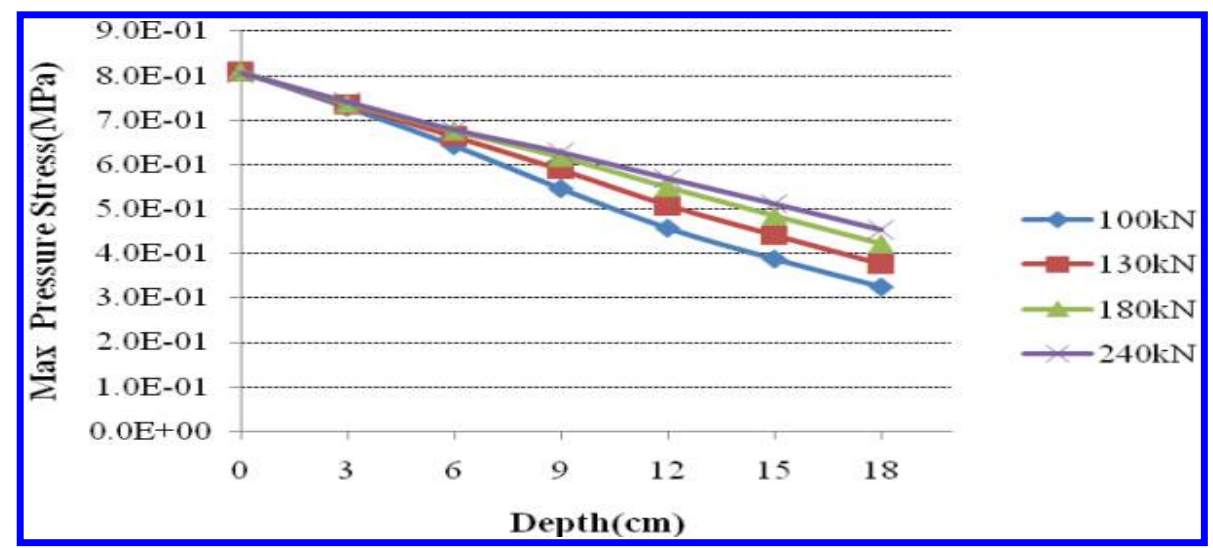

Figure 5. Maximum Pressure Stress Distribution in Suffice Layer

As is seen in Figure 5, the maximum pressure stress in the surface course increases with the accretion of the axle load. The heavier the axle load, the more slowly the maximum pressure stress will decrease with the depth of the layer. The difference in the maximum pressure stresses under different axle loads becomes the biggest in the bottom layer. So the pressure stress in the bottom layer is affected by the traffic loads greatly. When there is serious overloading, the pressure stress would exceed the stress that the bottom layer could bear. Therefore great permanent deformation would be developed in the bottom layer under overloading.

\section{FURTHER ANALYSIS}

It is concluded that the poor rutting-resistant property of the middle layer is the main reason why flowing ruts developed in sections 1 and 3 . The factors leading to the poor rutting-resistant property of the middle layer are researched subsequently. In general, the main internal factors which affect the rutting-resistant property of asphalt mixtures are voids, bitumen-aggregate ratio, and graduation. The influence of these factors on the property of the middle layer core samples is analyzed by One-Way Analysis of Variance. 


\section{Evaluation Index}

The $\mathrm{k}$ value is used to evaluate the results of Flow Number tests in this paper, so it is the evaluation index for the rutting-resistant property of cores.

The graduation of the asphalt mixture is evaluated with the Bailey method in this paper. The Bailey method supposes that a formative aggregate skeleton will provide an excellent rutting-resistant property for the asphalt mixture (William, 2002). The demarcation sieve size for coarse and fine aggregate, which is defined as primary control sieve size (PCS for short), changes with nominal maximum aggregate size. The parameter CA rate is put forward to evaluate the content of coarse aggregate and volume characteristics. CA rate reflects the balanced relationship between aggregate with $\mathrm{D} / 2 \sim$ PCS size and larger aggregate (William,2001). This relationship will affect the compaction characteristic and road performance of the asphalt mixture. The calculation formula is listed as follows:

$$
C A=\frac{P_{D / 2}-P_{P C S}}{100-P_{D / 2}}
$$

In the formula, $\mathrm{D}$ is nominal maximum aggregate size, $\mathrm{P}_{\mathrm{D} / 2}$ is the passing rate of the $\mathrm{D} / 2$ size sieve pore, $\mathrm{P}_{\mathrm{PCS}}$ is the passing rate of the primary control sieve, and $\mathrm{PCS}=0.22 \mathrm{D}$.

According to the partition method of Bailey for coarse and fine aggregate, the PCS of an AC-25 asphalt mixture of the middle layer is $4.75 \mathrm{~mm}$. The passing rate of $4.75 \mathrm{~mm}$ size sieve is defined as the index for dividing the AC-25 asphalt mixture into coarse type and fine type according to the technical specification of China for asphalt pavement construction. In this paper, CA rate and passing rate of $4.75 \mathrm{~mm}$ size sieve are used as the indexes to evaluate the graduation of the middle layer of the asphalt mixture.

\section{Indexes Analysis}

The voids, bitumen-aggregate ratio, passing rate of $4.75 \mathrm{~mm}$ size sieve and CA rate are shown in Table 5. One-Way Analysis of Variance is used to analyze whether the influence on $\mathrm{k}$ produced by these factors is significant. The significance level $\alpha$ is given 0.1 considering the variability of core samples. The significance index $\mathrm{P}<0.1$ means that the influence is significant. 
Table 5. Data of the Middle Layer Cores

\begin{tabular}{|c|c|c|c|c|c|c|}
\hline $\begin{array}{c}\text { Stake } \\
\text { Number }\end{array}$ & Site & $\mathbf{K}$ & $\begin{array}{c}\text { Voids } \\
(\%)\end{array}$ & $\begin{array}{c}\text { Bitumen-Aggregate } \\
\text { Ratio } \\
(\%)\end{array}$ & $\begin{array}{c}\text { Passing } \\
\text { Rate of } \\
4.75 \mathrm{~mm} \\
\text { Sieve } \\
(\%)\end{array}$ & CA \\
\hline \multirow[t]{4}{*}{$\mathrm{K} 33+960$} & Wheel Path & 65 & 2.23 & 4.57 & 46.5 & 1.01 \\
\hline & $\begin{array}{c}\text { Non-Wheel } \\
\text { Path }\end{array}$ & 66 & 2.97 & 5.48 & 46.2 & 1.27 \\
\hline & Shoulder & 30 & 3.00 & 4.43 & 42.6 & 1.06 \\
\hline & Shoulder & 14 & 3.71 & 4.85 & 41.3 & 1.29 \\
\hline \multirow[t]{4}{*}{$\mathrm{K} 80+440$} & Wheel Path & 34 & 0.57 & 4.21 & 36.9 & 0.56 \\
\hline & $\begin{array}{c}\text { Non-Wheel } \\
\text { Path }\end{array}$ & 45 & 2.09 & 4.94 & 38.1 & 0.68 \\
\hline & Shoulder & 34 & 4.27 & 4.45 & 37.4 & 0.58 \\
\hline & Shoulder & 34 & 5.50 & 3.99 & 37.8 & 0.77 \\
\hline \multirow[t]{3}{*}{$\mathrm{K} 221+780$} & Wheel Path & 29 & 1.66 & 4.03 & 47.8 & 1.42 \\
\hline & $\begin{array}{c}\text { Non-Wheel } \\
\text { Path }\end{array}$ & 18 & 2.02 & 6.04 & 47.4 & 1.54 \\
\hline & Shoulder & 24 & 5.65 & 4.12 & 45.1 & 1.11 \\
\hline \multirow[t]{4}{*}{$\mathrm{K} 222+630$} & Wheel Path & 5 & 3.88 & 5.40 & 44.3 & 1.28 \\
\hline & $\begin{array}{c}\text { Non-Wheel } \\
\text { Path }\end{array}$ & 4 & 4.73 & 4.88 & 42.9 & 1.29 \\
\hline & Shoulder & 6 & 7.06 & 5.93 & 43.7 & 0.85 \\
\hline & Shoulder & 12 & 7.10 & 3.84 & 44.4 & 0.94 \\
\hline
\end{tabular}

Parameters in Table 5 are divided into two or three levels, as shown in Table 6. The analysis results are shown in Table 7.

Table 6. Levels for Each Parameter

\begin{tabular}{c|c|c}
\hline Parameter & Dividing Line & Level Numbers \\
\hline Voids & $3 \%, 5 \%$ & 3 \\
bitumen-aggregate ratio & $4.5 \%$ & 2 \\
Passing rate of $4.75 \mathrm{~mm}$ sieve & $40 \%, 45 \%$ & 3 \\
CA & 1.0 & 2 \\
\hline
\end{tabular}

The results in Table 7 indicate that the void ratio and the passing rate of $4.75 \mathrm{~mm}$ sieve have a significant influence on $\mathrm{k}$, while CA and bitumen-aggregate ratio do not. Therefore, the passing rate of $4.75 \mathrm{~mm}$ sieve and voids are the main factors influencing the rutting-resistant property of the middle layer of an asphalt mixture. 
Table 7. Results of One-way Analysis of Variance

\begin{tabular}{c|c|c|c|c|c}
\hline Source & $\begin{array}{c}\text { Degree of } \\
\text { freedom }\end{array}$ & SS & MS & F & P \\
\hline Passing rate of & 2 & 2643 & 1322 & 5.81 & 0.017 \\
4.75mm sieve & 12 & 2729 & 227 & & \\
Error & 14 & 5372 & & & \\
Sum & 2 & 2206 & 1103 & 4.18 & 0.042 \\
Voids & 12 & 3166 & 264 & & \\
Error & 14 & 5372 & & & \\
Sum & 1 & 0 & 0 & 0.00 & 0.980 \\
Bitumen-Aggregate Ratio & 13 & 5372 & 413 & & \\
Error & 14 & 5372 & & & \\
Sum & 1 & 3 & 3 & 0.01 & 0.939 \\
CA Rate & 13 & 5370 & 413 & & \\
Error & 14 & 5372 & & & \\
Sum & 14 &
\end{tabular}

\section{CONCLUSION}

The causes of rutting distresses in the Yi-Huai-Jiang Expressway are analyzed by evaluating two factors: the rutting-resistant property of the surface course and traffic loads. First, the rutting-resistant property of core samples is evaluated by experiments. Then the causes are determined by comparing the heavy-rutting sections and light-rutting sections. Finally. the factors which significantly influence the rutting-resistant property of the middle layer of an asphalt mixture in the Shanghai-Beijing direction are obtained.

The main conclusions are as follows:

1. The rutting distress in sections 1 and 3 is flowing ruts and mainly occur in the middle layer. The cause of ruts is the poor rutting-resistant property of the middle layer, and the main factors influencing the rutting-resistant property are the passing rate of $4.75 \mathrm{~mm}$ sieve and voids.

2. The rutting distress in sections 5 and 7 is compacting ruts and mainly occur in the bottom layer. The cause of rutting is the overloading which exerts too large of a pressure stress on the bottom layer, leading to its permanent deformation.

\section{REFERENCE}

Kaloush E. K. and Witczak W. M. (2003). Simple Performance Test for Permanent Deformation of Asphalt Mixtures, Transportation Research Record, 00993.

Liu, B. (2008). Analysis of Traffic, Volume, Axle Load and Traffic Characteristics in Jinghu Expressway Jiangsu Section, Southeast University, Nanjing, P.R.China (in Chinese). 
NCHRP. (2003). Simple Performance Test for Superpave Mix Design: First-Article Development and Evaluation(Project D09-29 FY'01), NCHRP REPORT 513, Transportation Research Board.

Sha, Q. (2001). Introduce and Prevention of Distress in Initial Stage of Asphalt Pavement, Beijing, P.R.China (in Chinese).

William R. V., William J. P., Samuel H C. (2002). Bailey method for gradation selection in HMA mixture design, Transportation Research Circular Number E-C044.

William R. V., William J. P., Samuel H. C. (2001). Aggregate blending for asphalt mix design Bailey method, Transportation Research Record, 1789:146-153. 